\title{
Growth Time Effect on the Structural and Sub-structural Properties of Chemically-deposited ZnO films
}

\author{
Taisiia O. Berestok ${ }^{1, a^{*}}$, Denys I. Kurbatov ${ }^{1, b}$, Anatoliy S. Opanasyuk ${ }^{1, c}$, \\ Andreu Cabot ${ }^{2,3, d}$, Hyeonsik Cheong ${ }^{4, e}$ \\ ${ }^{1}$ Sumy State University, Rimsky-Korsakov Str., 2, Sumy, Ukraine \\ ${ }^{2}$ Catalonia Energy Research Institute - IREC, Jardí de les Dones de Negre 1, Sant Adria del \\ Besos, 08930, Spain \\ ${ }^{3}$ Institució Catalana de Recerca i Estudis Avançats (ICREA), 08010 Barcelona, Spain \\ ${ }^{4}$ Sogang University, 35 Baekbeom-ro, Mapo-gu, Seoul 121-742, South Korea \\ ataisia.berestok@ukr.net, ${ }^{b}$ kurd@ukr.net, copanasyuk_sumdu@ukr.net, ${ }^{\mathrm{d}}$ acabot@irec.cat, \\ hcheong@sogang.ac.kr
}

Keywords: ZnO, Nanorods, Chemical synthesis, X-ray diffraction, Structural and Substructural studies.

\begin{abstract}
Nanostructured $\mathrm{ZnO}$ films are obtained by chemical bath deposition from zinc nitrate, hexamethylenetetramine and ammonia. The evolution of the structural and sub-structural properties of the films is characterized using high resolution scanning electron microscopy (SEM) and X-ray diffraction analysis. In particular, we detail here the influence of condensation time on the crystal phase, texture quality, lattice constants, grain size, coherent scattering domain size (CSD), microstrain, stress and concentration of dislocations. Obtained condensates have the wurtzite structure with lattice parameters in the range $a=0.3248-0.3254 \mathrm{~nm}$ and $c=0.5206-0.5214 \mathrm{~nm}$, depending on the condensation time. The grain size and microstrain in the direction perpendicular to the crystallographic planes (002) are in the range $L \sim 26-42 \mathrm{~nm}$ and $\varepsilon \sim(0.59-3.09) \cdot 10^{-3}$, respectively. Furthermore, the effects of deposition time on microstrain, stress and concentration of dislocations in the layers is established. By adjusting the condensation time, we are able to produce $\mathrm{ZnO}$ films with controlled structural properties: from nanorods to continuous nanostructured films.
\end{abstract}

\section{Introduction}

The excellent properties and the related broad range of applications of $\mathrm{ZnO}$ have stimulated intensive studies on this material. Owing to the large exciton binding energy $(60 \mathrm{meV})$ of $\mathrm{ZnO}$, it has been proposed for effective laser generation at room temperature [1]. The large band gap of $\mathrm{ZnO}$ allows effectively absorbing of ultraviolet light, making it a promising material for UV detectors and filters. Also due to its high radiation, chemical, and thermal stability [2], $\mathrm{ZnO}$ is widely used for gas sensing, light-emitting diodes, varistors, etc [3]. $\mathrm{ZnO}$ is also a promising material for the antireflective, conductive and window layers of large area solar cells based on absorbing layers of $\mathrm{Si}$, CdTe, CIGS or CZTSe [4]. Also, zinc oxide is considered as one of the most promising photocatalysts for water and air.

Another important advantage of $\mathrm{ZnO}$ is the possibility to grow nanostructured films controlled structural characteristics using non-vacuum, low-temperature and thus low-cost methods such as hydrothermal synthesis [5, 6], electrodeposition [7, 8, 9, 10, 11], sol-gel method [12], spray pyrolysis [13] and chemical bath deposition (CBD) $[14,15,16,17]$. The latter technique is one of the most promising due to its simplicity, efficiency and the possibility to produce $\mathrm{ZnO}$ films on different types of substrates including flexible, large area substrates.

However, for practical use of $\mathrm{ZnO}$ films it is necessary to be able to precisely and reliably control their optical, electrical, and physical characteristics, which depend on the ZnO structure and substructure parameters. To realize a wide range of devices it is important to establish the corelation 
between the deposition conditions (deposition time, source precursors) and morphology and structural characteristics of obtained condensates.

There are a number of reports devoted to the investigation of structural properties of $\mathrm{ZnO}$ deposited by different methods [18, 19, 20, 21, 22]. However, the structural and sub-structural characteristics of CBD-grown $\mathrm{ZnO}$ layers have not been thoroughly investigated. Here, we present the results of our comprehensive study of the structural and sub-structural features of $\mathrm{ZnO}$ films prepared by CBD under controlled physical and chemical conditions.

\section{Experimental details}

Nanostructured $\mathrm{ZnO}$ films were prepared using CBD by immersing the precleaned glass substrates in a chemical reactor with a solution of zinc nitrate hexahydrate precursor $(0.1 \mathrm{M})$ $\left(\mathrm{Zn}\left(\mathrm{NO}_{3}\right)_{2} \cdot 6 \mathrm{H}_{2} \mathrm{O}\right)$ and hexamethylenetetramine $\left(\mathrm{C}_{6} \mathrm{H}_{12} \mathrm{~N}_{4}\right)$. Details of the procedure are described in

Ref. 22. The deposition was carried out at a bath temperature of $90^{\circ} \mathrm{C}$. Since the surface morphology of zinc oxide condensates largely depends on the time of deposition, the duration of film deposition, $\tau$, was varied in the range from 30 to $120 \mathrm{~min}$. The $\mathrm{pH}$ of the solution was maintained at 10 by adding the appropriate amount of ammonia $\left(\mathrm{NH}_{4} \mathrm{OH}\right)$.

Structural investigations of the samples were carried out using an X-ray diffractometer (Bruker D8 Advance) with Ni-filtered $\mathrm{K} \alpha$ - radiation of copper anode in a range of angles $20^{\circ}<2 \theta<80^{\circ}$, where $2 \theta$ is the Bragg angle. XRD patterns were normalized to the intensity of the (002) peak of the hexagonal $\mathrm{ZnO}$ phase. Phase analysis was performed by comparing interplanar distances and relative intensities of the investigated samples with the standard according to JCPDS 79-0207 [23]. The X-ray radiation was focused according to the Bragg-Brentano method.

The texture quality of the $\mathrm{ZnO}$ films was estimated using Harris method [24-25]. The pole density was calculated using the equation: $P_{i}=\frac{\left(I_{i} / I_{0 i}\right)}{\frac{1}{N} \sum_{i=1}^{N}\left(I_{i} / I_{0 i}\right)}$, where $I_{i}$ and $I_{0 i}$ are the integral intensity of the $i$ - diffraction peak for the film samples and the standards, respectively; and $N$ is the number of lines in the diffraction pattern. Thereafter we built the dependences $P_{i}-(h k l)_{i}$ and $P_{i}-\varphi$, where $\varphi$ is the angle between the chosen direction and normal to different crystallographic planes, which correspond to the reflection in the XRD pattern, $(h k l)_{i}$. This angle was calculated for the hexagonal lattice, using the equations given in Ref. 25. The axis of the texture has indexes corresponding to the maximal value of $P_{i}$. The orientation factor was estimated via equation $f=\sqrt{\frac{1}{N} \sum_{i=1}^{N}\left(P_{i}-1\right)^{2}}$. Determination of the interplanar distances of the wurtzite structure of $\mathrm{ZnO}$ was performed from the position of $\mathrm{K} \alpha 1$ component of all of the most intense lines present in the XRD pattern.

The lattice constants, $a$ and $c$, of the hexagonal phase were calculated using:

$$
\begin{gathered}
a=\frac{\lambda}{2 \sin \theta} \sqrt{\frac{4}{3}\left(h^{2}+h k+k^{2}\right)+\left(\frac{a}{c}\right)^{2} l^{2}}, \\
c=\frac{\lambda}{2 \sin \theta} \sqrt{\frac{4}{3}\left(\frac{c}{a}\right)^{2}\left(h^{2}+h k+k^{2}\right)+l^{2}}
\end{gathered}
$$

where $\lambda$ is the X-rays wavelength. The ratio $c / a$ was considered constant and equal to the value of the ideal wurtzite structure, $\mathrm{c} / \mathrm{a}=1.601$ [23].

The values of the lattice constants of $\mathrm{ZnO}$ were further clarified using the extrapolation method of Nelson-Riley [24-25]. At the same time we used the graphical method of successive approximations, which included an iterative procedure. From the dependences $a(c)$ vs. $1 / 2 \cos ^{2} \theta(1 / \sin \theta+1 / \theta)$ we determined the values of lattice parameters, $a$ and $c$, and the ratio $c / a$. 
The calculated ratio $c / a(a / c)$ was used to estimate new constants from equations (1) and (2). Thereafter, an iterative procedure was repeated several times (up to four), until the obtained values, $a, c$, and $c / a$, converged [25]. The approximation of the points in $a(c)-1 / 2 \cos ^{2} \theta(1 / \sin \theta+1 / \theta)$ dependencies was made with the help of the least-squares method. Using this procedure has allowed to significantly increase the accuracy of the lattice constant determination and to calculate the ratio of $c / a$, which was impossible using X-ray methods.

The values of $a$ and $c$ obtained after the fourth iteration were used to calculate the volume of the hexagonal primitive cell using $V=\left(3 \sqrt{3} a^{2} \mathrm{c}\right) / 2$. The $\mathrm{Zn}-\mathrm{O}$ bond length was determined via the equation given in Ref. 26.

The diffractometrical method was also used to estimate the average values of the coherent scattering domain size (CSD) $L$ and microstrain $(\varepsilon)$ from the half-width of the diffraction lines. Traditionally, determining of the crystallites size is carried out using electron microscopy or X-ray diffraction with the help of Scherrer equation $[18,21,22]$. This leads to some overstatement of the results, because the authors neglected the presence of micro strain in the films. To separate the diffraction broadening caused by physical and instrumental effects, we used approximations of the X-ray line by Cauchy and Gauss functions. Further separation of contributions from dispersion on CSD and microstrain was performed by the graphical method of Williamson-Hall. Accordingly, it was built the graphics in coordinates $\beta \cos \theta / \lambda-(4 \sin \theta / \lambda)$ and $(\beta \cos \theta / \lambda)^{2}-(4 \sin \theta / \lambda)^{2}$, where $\beta$ is the physical broadening of X-ray line [25]. Additionally, microstrain and the CSD size were determined by the method of approximation of the X-ray line as a threefold convolution [2728]:

$$
\begin{aligned}
& L=\frac{\lambda}{\cos \theta_{1}} \cdot \frac{t B_{1}-c B_{2}}{t \beta_{f 1}^{2}-\beta_{f 2}^{2}}, \\
& \varepsilon^{2}=\frac{c \beta_{f 1}^{2} B_{2}-\beta_{f 2}^{2} B_{1}}{16 \operatorname{tg} \theta_{1}\left(c B_{2}-t B_{1}\right)},
\end{aligned}
$$

where $t=\frac{\operatorname{tg}^{2} \theta_{2}}{\operatorname{tg}^{2} \theta_{1}} ; c=\frac{\cos \theta_{1}}{\cos \theta_{2}} ; \beta_{f i}=\sqrt{\left(B_{i}\right)^{2}-\left(b_{i}\right)^{2}} ; \theta_{1}$ and $\theta_{2}$ are the diffraction angles of the pairs of analyzed lines; and $B_{i}, b_{i}, \beta_{f i}$ are the measured, instrumental and physical broadening of the corresponding XRD peaks, respectively. Stress was calculated by the formula $\sigma=E \varepsilon$, where $E$ is the Young's modulus, which for the hexagonal lattice is determined from [20]:

$$
E_{h k l}=\frac{\left[h^{2}+\frac{(h+2 k)^{2}}{3}+\left(\frac{a l}{c}\right)^{2}\right]^{2}}{s_{11}\left(h^{2}+\frac{(h+2 k)^{2}}{3}\right)^{2}+s_{33}\left(\frac{a l}{c}\right)^{4}+\left(2 s_{13}+s_{44}\right)\left(h^{2}+\frac{(h+2 k)^{2}}{3}\right)\left(\frac{a l}{c}\right)^{2}},
$$

where $s_{11}, s_{13}, s_{33}, s_{44}$ are the elastic compliances of $\mathrm{ZnO}$.

These constants were found with the help of the known values of elastic stiffness constants $c_{i j}$ of the material $\left(c_{11}=209.70 \mathrm{GPa}, c_{12}=121.10 \mathrm{GPa}, c_{44}=42.47 \mathrm{GPa}\right)$ [29]. In addition, for calculations we used experimentally determined values of the lattice constant $a, c$ (after 4 iterations) of samples obtained after deposition time of $120 \mathrm{~min}$.

Further, on the basis of calculations of CSD and microstrain, we estimated the average dislocation density in $\mathrm{ZnO}$ films. The average dislocation density, which forms the boundaries of the blocks, is $\rho_{L}=\frac{3 n}{L^{2}}$ [30], where $n$ is the number of dislocations in each of the six faces of the block. If dislocations are located mainly inside of CSD, the dislocation density is calculated by $\rho_{\varepsilon}=\frac{4}{F}\left(\frac{2 \varepsilon}{d_{0}}\right)^{2}$ [30], where $F$ is a number that takes into account how many times the dislocation 
energy grows under interaction with other dislocations; and $d_{0}$ is the lattice period of the material in the appropriate direction. Taking $n=F=1$, the lower bound for $\rho_{L}$ and the upper bound for $\rho_{\varepsilon}$ can be estimated.

To determine the total concentration of dislocations we used the following equation: $\rho=\frac{15 \varepsilon}{d_{0} L}[31]$. These estimations allowed us to calculate the concentration of dislocations in the CSD bulk and on their boundaries, and the total concentration of dislocations.

\section{Results and discussion}

Figure 1 displays SEM images of the surface of $\mathrm{ZnO}$ nanostructured films obtained after different deposition time. At the initial stage of the deposition, nanostructures in the form of hexagonal prisms were formed onto glass substrates. After deposition for $60 \mathrm{~min}$, a densely packed array of $\mathrm{ZnO}$ nanorods with a hexagonal prism shape formed with diameters in the range of $0.2-0.9 \mu \mathrm{m}$ and lengths in the range of $2.0-3.5 \mu \mathrm{m}$ was obtained. $\mathrm{ZnO}$ nanorods grew at various angles to the substrate. When the deposition time was increased to $90 \mathrm{~min}$, an increase in nanorod thickness (1.0 $1.9 \mu \mathrm{m})$ and length $(4.8-6.7 \mu \mathrm{m})$ occurred. In addition, there is a reduction of intervals between them. Further growth of the films occurred through the nucleation on the surface of the nanorods, which led to their branching. Increasing the deposition time up to $120 \mathrm{~min}$ caused a change of growth mechanism and resulted in the formation of laminar crystallites with thickness in the range $0.10-0.16 \mu \mathrm{m}$ and a much greater length and width. As a result, the formation of highly porous labyrinthine layer film of zinc oxide is occurred.



Figure 1. SEM images of $\mathrm{ZnO}$ films obtained at condensation time $\tau: 60 \mathrm{~min}(\mathrm{a}, \mathrm{b}), 90 \mathrm{~min}(\mathrm{c})$, $120 \min (d)$ 
The XRD patterns of the ZnO layers are presented in Figure 2a. The phase analysis showed that reflections from the crystallographic plane (002) of the hexagonal phase of $\mathrm{ZnO}$ had maximal intensity. This indicated the presence of growth texture [002] in the films. Also in the diffraction patterns we registered fairly intense lines at angles $31.65^{\circ}, 36.13^{\circ}$, and $47.52^{\circ}$, which were identified as reflections from (100), (101), (102) planes, respectively, of the $\mathrm{ZnO}$ wurtzite structure [23, JCPDS 79-0207].
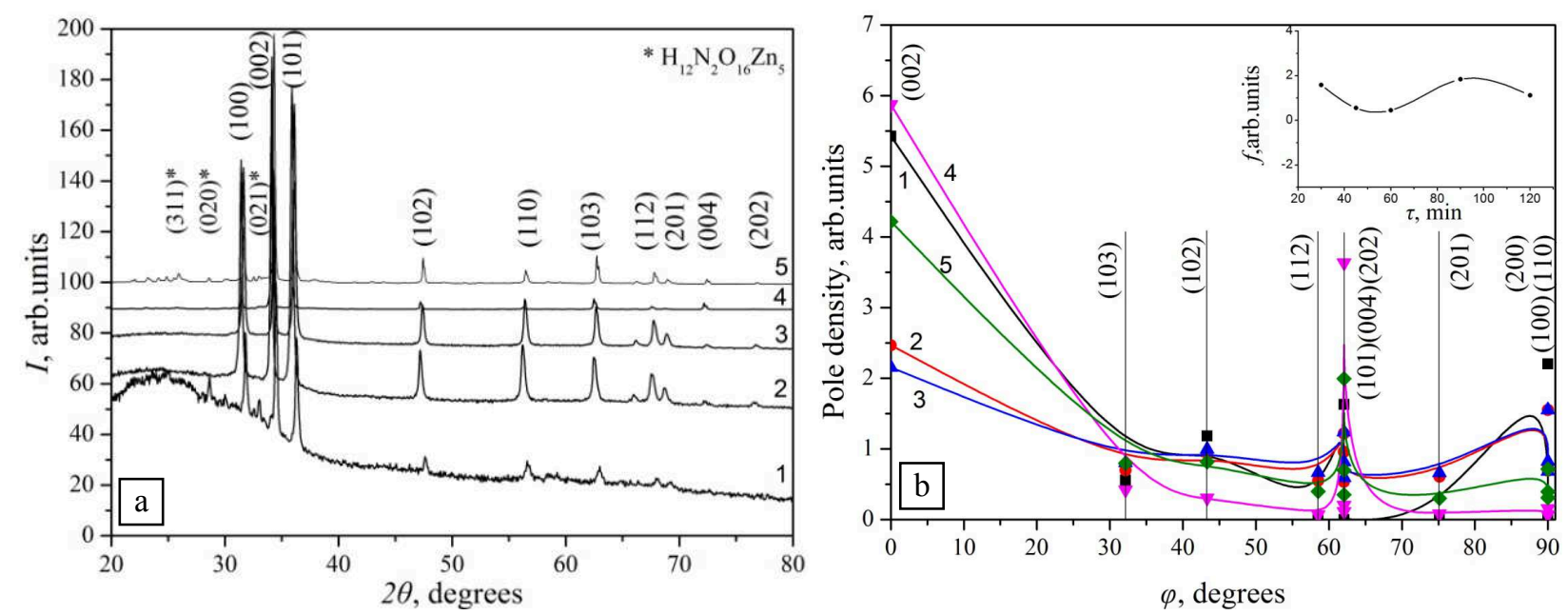

Figure 2. XRD patterns (a) and dependence of the pole density $P_{i}$ and orientation factor $f$ (in the inset) on the angle $\varphi$ between the texture axis and the normal to the reflection plane for $\mathrm{ZnO}$ films obtained at $\tau=30 \min (1), 45 \min (2), 60 \min (3), 90 \min (4)$ and $120 \min (5)$ (b)

In the XRD patterns of $\mathrm{ZnO}$ with small thickness (condensation time $<45 \mathrm{~min}$ ) peaks at angles $26.03^{\circ}, 28.72^{\circ}$, and $32.99^{\circ}$ from another phase were present. They were identified as reflections of the (311), (020), (021) planes, respectively, of $\mathrm{H}_{12} \mathrm{~N}_{2} \mathrm{O}_{16} \mathrm{Zn}_{5}$ compound [32, JCPDS 024-1460]. The presence of other phases may be due to incorporation during the chemical reaction of residual sediment into the crystalline structure of the condensation product.

As a result of the calculation of the pole density and orientation factor of the hexagonal phase of zinc oxide films (Fig. 2b), we confirmed the existence of [002] axial texture growth in the layers. This growth texture is typical for $\mathrm{ZnO}$ films obtained by chemical bath deposition from a solution of zinc nitrate and ammonia [14] and zinc acetate and ammonia [15]. The dependence of the orientation factor $f$ on condensation time is given in Figure 2(b). The quality of the texture initially decreased as deposition time increased, and then with further increase of deposition time and film thickness, the value of the orientation factor increased, indicating improvement of the crystalline quality. We observed similar dependence in the condensates deposited from solutions of zinc sulphate and ammonia [33].

It is important to determine precisely the lattice parameters, because the value of lattice constant is extremely sensitive to changes in stoichiometry of the films and embedded of impurities in the crystal structure of the condensate. Traditionally, authors determine the lattice constants of $\mathrm{ZnO}$ using equation given in [35] in which they substituted reference value of $c / a$ [27]. As a result the accuracy of lattice constants calculating is low. Moreover it is impossible to determine the ratio of $c / a$ for obtained sample. To improve the accuracy of measurement of lattice constants $(a, c)$ of the material we proposed a method for their determination, including the iterative procedure described above. As a result of calculations, it was found that the values of lattice constants $a, c$ and their ratio $c / a$ converged after the fourth iteration, indicating about the finishing of calculation procedure. 

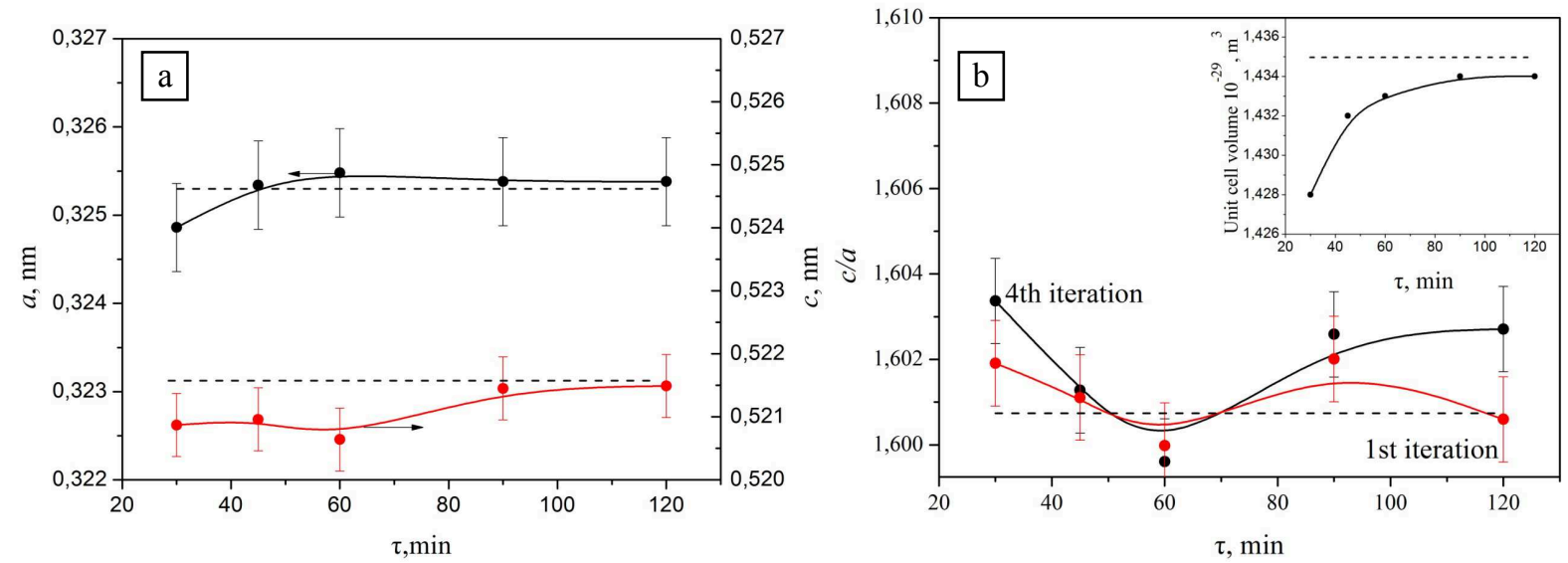

Figure 3. Dependences of lattice constants $a$ and $c$ (fourth iteration) estimated by Nelson-Riley method (a), c/a ratio (first and fourth iteration) on deposition time of $\mathrm{ZnO}$ films (b). The inset (b) shows the dependence of unit cell volume of $\mathrm{ZnO}$ on deposition time

Figure 3(a) presents the dependence of the lattice constants on the condensation time. The dotted lines in the figure correspond to the values given in Ref. 23 for the stoichiometric case. It was found that the lattice constants $a, c$ and the ratio $c / a$ were practically unchanged after the fourth iteration, confirming the validity of the procedure for determination of the lattice parameters. The lattice constants of the thinnest $\mathrm{ZnO}$ layers $(\tau=30 \mathrm{~min}$ ) were $a=0.32486 \mathrm{~nm}, c=0.52087 \mathrm{~nm}$ (Table 1), which were smaller than the reference values $(a=0.3256 \mathrm{~nm}, c=0.5212 \mathrm{~nm})$ [23, JCPDS 790207]. However, with increasing film thickness, the estimated values $(a=0.32538 \mathrm{~nm}, c=0.52149$ $\mathrm{nm})$ approached the reference data.

The volume of the hexagonal primitive cell in $\mathrm{ZnO}$ films (inset of Fig. 3 b) was calculated from the estimated lattice parameters. We found that increasing the deposition time from $\tau=30 \mathrm{~min}$ to $\tau$ $=120 \mathrm{~min}$ lead to an increase of the cell volume from $V=1.428 \cdot 10^{-29} \mathrm{~m}^{-3}$ to $V=1.434 \cdot 10^{-29} \mathrm{~m}^{-3}$. Simultaneously, the bond lengths between atoms of zinc and oxygen varied from $l=0.19775 \mathrm{~nm}$ to $l=0.19804 \mathrm{~nm}$ (Table 1). These values are close to the reference one for solid material $(l=0,19778$ $\mathrm{nm})$.

As it mentioned, traditionally to determine CSD size in $\mathrm{ZnO}$, authors use Scherrer equation [18, 21, 22]. Despite that, to estimation of substructural characteristics, we use the method of Williamson-Hall method. Furthermore to determine CSD size, method of threefold convolution is used, which is more accurate.

Table 1 - The calculations results of lattice constants, unit cell volume, stress and dislocation density in the films

\begin{tabular}{|c|c|c|c|c|c|c|c|c|c|}
\hline $\begin{array}{c}\tau \\
{[\mathrm{min}]}\end{array}$ & $\begin{array}{c}a \\
{[\mathrm{~nm}]}\end{array}$ & $\begin{array}{c}c \\
{[\mathrm{~nm}]}\end{array}$ & $c / a$ & $\begin{array}{c}l \\
{[\mathrm{~nm}]}\end{array}$ & $\begin{array}{c}V \cdot 10^{-29} \\
{\left[\mathrm{~m}^{3}\right]}\end{array}$ & $\sigma 10^{8}[\mathrm{~Pa}]$ & $\begin{array}{c}\rho_{L} 10^{-15} \\
{\left[\operatorname{lin} / \mathrm{m}^{2}\right]}\end{array}$ & $\begin{array}{c}\rho_{\varepsilon} 10^{-14} \\
{\left[\mathrm{lin} / \mathrm{m}^{2}\right]}\end{array}$ & $\begin{array}{c}\rho_{L \varepsilon} 10^{-16} \\
{\left[\mathrm{lin} / \mathrm{m}^{2}\right]}\end{array}$ \\
\hline 30 & 0.32486 & 0.52087 & 1.603 & 0.19775 & 1.428 & 4.46 & 1.72 & 22.50 & 4.27 \\
\hline 45 & 0.32534 & 0.52096 & 1.601 & 0.19796 & 1.432 & 2.45 & 3.34 & 6.80 & 3.26 \\
\hline 60 & 0.32548 & 0.52064 & 1.600 & 0.19798 & 1.433 & 1.69 & 3.91 & 3.24 & 2.43 \\
\hline 90 & 0.32538 & 0.52145 & 1.603 & 0.19804 & 1.434 & - & - & - & - \\
\hline 120 & 0.32538 & 0.52149 & 1.603 & 0.19804 & 1.434 & 0.86 & 3.47 & 0.83 & 7.94 \\
\hline$[17]$ & 0.3256 & 0.5212 & 1.601 & 0.19810 & 1.435 & & & & \\
\hline
\end{tabular}

Estimations of substructural parameters of the obtained films were carried in the directions of $a$ (by reflections from the (100) plane) and $c$ (by reflections from the (002) plane) axes of $\mathrm{ZnO}$ hexagonal phase and in the direction that is at the angle of $61.6^{\circ}$ to the $c$ axis (by reflections from the (101) plane). The results of calculations of CSD and microstrain in these crystallographic directions are summarized in Table 2. 
Table 2 - Sub-structural features of $\mathrm{ZnO}$ films obtained using different approximations

\begin{tabular}{|c|c|c|c|c|c|c|c|}
\hline \multirow{3}{*}{$\tau, \min$} & \multirow{3}{*}{$(h k l)$} & \multicolumn{3}{|c|}{$L[\mathrm{~nm}]$} & \multicolumn{3}{|c|}{$\varepsilon \cdot 10^{3}$} \\
\hline & & \multicolumn{2}{|c|}{ Approximation by } & \multirow{2}{*}{$\begin{array}{c}\text { From } \\
\text { convolution }\end{array}$} & \multicolumn{2}{|c|}{ Approximation by } & \multirow{2}{*}{$\begin{array}{c}\text { From } \\
\text { convolution }\end{array}$} \\
\hline & & Gauss & Cauchi & & Gauss & Cauchi & \\
\hline \multirow{2}{*}{30} & $(002)-(004)$ & 61.8 & 36.5 & 41.7 & 2.68 & 3.55 & 3.09 \\
\hline & $(101)-(202)$ & 30.1 & 26.3 & 26.6 & 6.89 & 1.84 & 1.09 \\
\hline \multirow{3}{*}{45} & $(100)-(200)$ & 32.6 & 27.2 & 27.6 & 1.19 & 2.49 & 1.93 \\
\hline & (002)-(004) & 35.6 & 29.3 & 29.9 & 1.04 & 2.18 & 1.69 \\
\hline & $(101)-(202)$ & 34.5 & 28.0 & 28.6 & 1.12 & 2.26 & 1.77 \\
\hline \multirow{3}{*}{60} & (100)-(200) & 35.8 & 28.6 & 29.3 & 1.41 & 2.66 & 2.10 \\
\hline & $(002)-(004)$ & 30.4 & 27.5 & 27.6 & 0.46 & 1.58 & 1.17 \\
\hline & (101)-(202) & 30.3 & 26.9 & 27.1 & 0.57 & 1.69 & 1.27 \\
\hline 90 & $(100)-(200)$ & 27.3 & 26.1 & 26.1 & 0.12 & 1.16 & 0.82 \\
\hline \multirow{3}{*}{120} & $\begin{array}{l}(100)-(200) \\
\end{array}$ & 29.1 & 27.9 & 27.9 & 0.068 & 1.03 & 0.72 \\
\hline & $\begin{array}{l}(002)-(004) \\
\end{array}$ & 30.5 & 29.3 & 29.3 & 0.007 & 0.85 & 0.59 \\
\hline & (101)-(202) & 36.9 & 30.2 & 30.9 & 0.97 & 2.04 & 1.59 \\
\hline
\end{tabular}

As it is shown in Table 2, the values of substructural parameters, obtained with the help of different approximations, correlated well with each other, as it should be on theoretical considerations. This demonstrated the reliability of the results.

The results of CSD calculation in the direction perpendicular to the crystallographic planes (002), (101), (100) and the microstrain in the same directions obtained using the threefold convolution are shown in Fig. 4. It was found that increasing the condensation time of thin films resulted in a decrease of CSD from $L \sim 42 \mathrm{~nm}$ to $L \sim 26 \mathrm{~nm}$ in the [002] direction, whereas the average value of CSD remained approximately constant $(L \sim 27-28 \mathrm{~nm})$ in the [100] crystallographic direction.
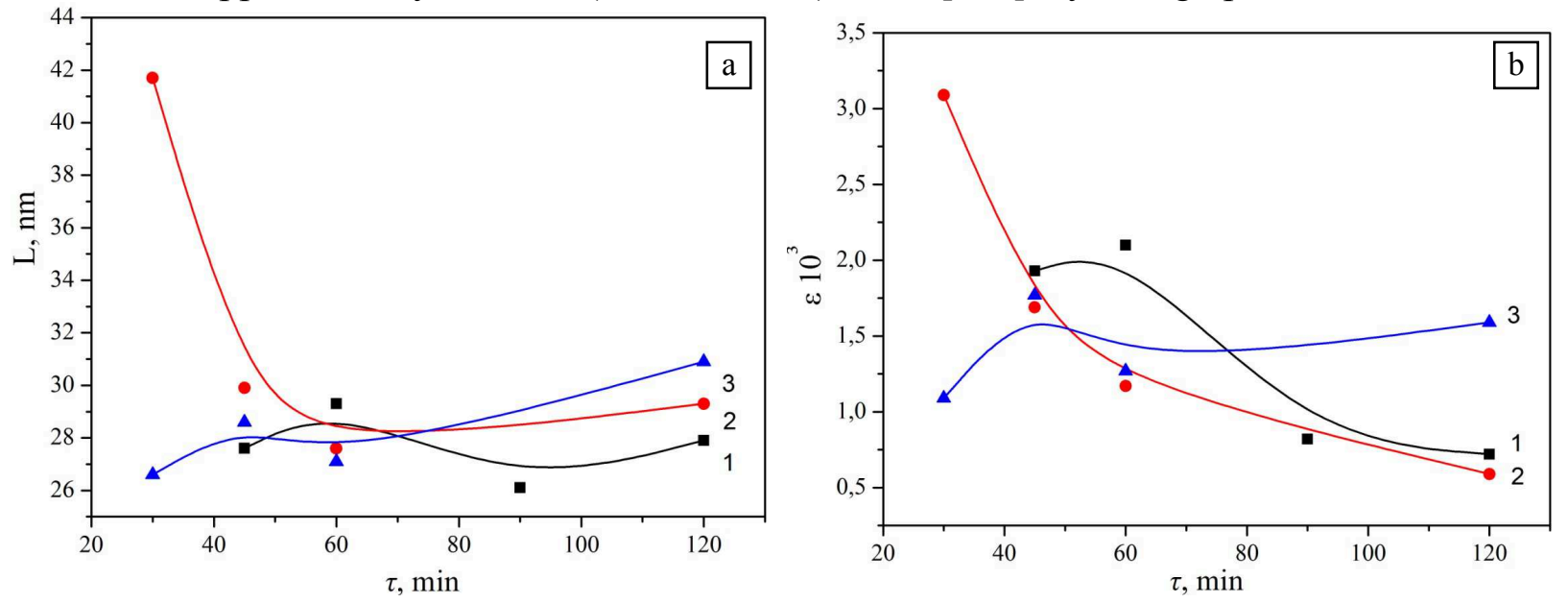

Figure 4. Effect of the deposition time on CSD $L$ (a) and the microstrain $\varepsilon$ (b) of $\mathrm{ZnO}$ films obtained using threefold convolution in different crystallographic directions: 1 - (100); 2 - (002); 3 $(101)$

It should be noted that this behavior of $L$ is due to the details of the thin film growth process: at the initial stage of growth well-aligned nanorods were formed in the [002] direction; then the space between nanorods was filled by laminar crystallites. Using Scherrer equations $\mathrm{Z}$. Y. Wu et al. obtained similar values of CSD $(L=47 \pm 11 \mathrm{~nm})$ for $\mathrm{ZnO}$ films produced from solutions of zinc nitrate, ammonia and sodium hydroxide [16].

The microstrain in the [002] direction of $\mathrm{ZnO}$ layers decreased monotonically with increasing deposition time from $\varepsilon \sim 3.09 \cdot 10^{-3}$ to $\varepsilon \sim 0.59 \cdot 10^{-3}$ (Fig. 4(b)). The same behavior was observed for microstrains in the [100] direction, whereas in the [101] direction the microstrain slightly increased from $\varepsilon \sim 1.09 \cdot 10^{-3}$ to $\varepsilon \sim 1.59 \cdot 10^{-3}$ with increasing $\tau$.

Estimations of microstrain allowed to calculate stress $(\sigma)$ in the films, in the [002] direction. For this purpose, we used the value of Young's modulus that equals to $E=144 \mathrm{GPa}$ (calculated from Eq. 
(5)). It was established that microstress values varied in the range of $\sigma=86-446 \mathrm{MPa}$. The maximum value of $\sigma=446 \mathrm{MPa}$ was slightly higher than what was found by G. Sh. Thool et al. in zinc oxide films $(\sigma=277 \mathrm{MPa})$ deposited by chemical bath deposition from solutions of zinc acetate, trisodium citrate, triethanolamine and sodium hydroxide [34].

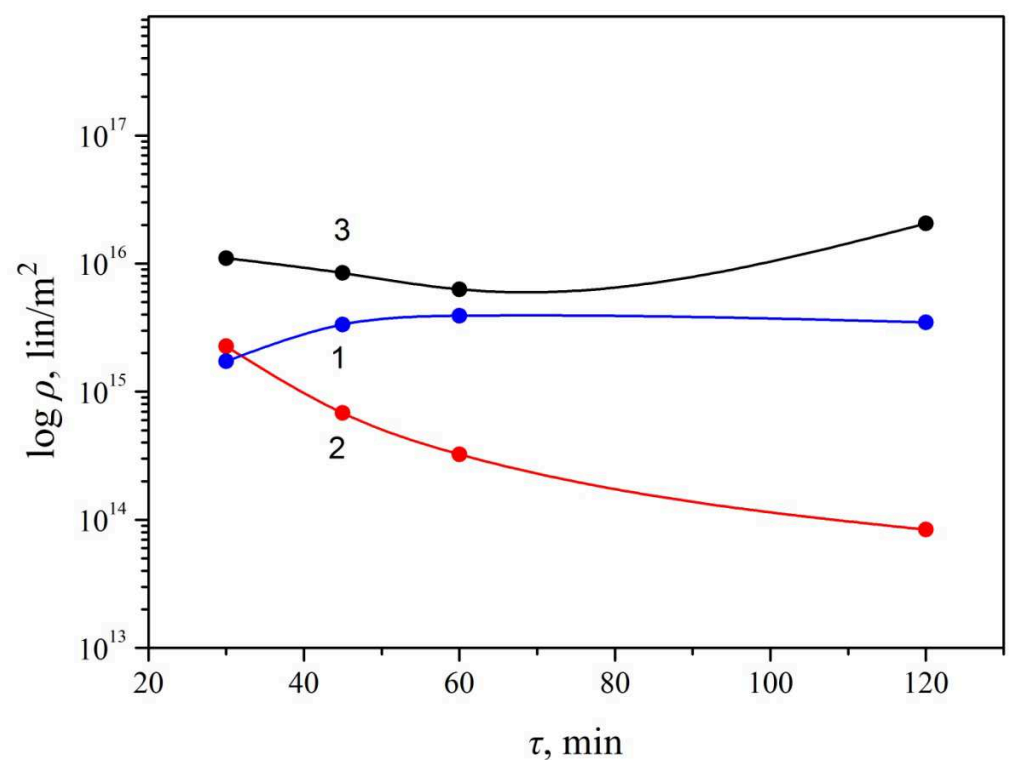

Figure 5. Dependence of dislocation density on deposition time: dislocations, which form the boundaries of the blocks (1); density of dislocations located mainly in the bulk of CSD (2); total concentration of dislocations in the material (3). Used reflexes (002)-(004)

In contrast to works, where authors calculate the averaged density of dislocations, which form the boundaries of the blocks [27], on the basis of CSD and microstrain calculations in the [002] direction we make an assessment of the total dislocation density in the samples, that includes both: averaged density of dislocations at the boundaries of the blocks and concentration of dislocations in the bulk of CSD (Table 1). (Table 1, Figure 5).

With increasing deposition time, the dislocation density in the bulk of CSD decreased, whereas the concentration of dislocations on the boundary of CSD slightly increased. As a result, the minimum of the total dislocation density was found for $\tau=70-80 \mathrm{~min}$. Calculations indicated that dislocations were mainly concentrated on the CSD boundaries, being the bulk of crystallites in the thin films almost free from dislocations. This is a particularly important result taking into account the important role that dislocation play in II-VI compounds limiting charge carrier lifetime and the strong dependence on location that recombination centers have.

\section{Conclusions}

We reported a comprehensive study of the structural (texture quality and lattice constants) and sub-structural (coherent scattering domain size, microstrains, and dislocation density) characteristics of nanostructured $\mathrm{ZnO}$ films obtained by chemical bath deposition from zinc nitrate, hexamethylenetetramine and ammonia for different condensation time. It was established that growth of condensates occurred through the formation of nanorods, followed by filling the gaps with laminar crystallites with increasing duration of deposition. Thus by adjusting the deposition time, $\mathrm{ZnO}$ films with controlled structural properties could be obtained: from nanorods to continuous nanostructured films.

It was shown that $\mathrm{ZnO}$ films were mostly single-phased and had hexagonal structure with [002] growth texture. The crystalline quality of the films depended on the time of deposition. Using the Nelson-Riley extrapolation method and iterative procedure, the precise values of lattice constants of the material $(a=0.3248-0.3254 \mathrm{~nm}, c=0.5206-0.5214 \mathrm{~nm})$ and their ratio $(c / a=1.600-1.603)$ were calculated. CSD and microstrain in the direction perpendicular to the (002) crystallographic 
planes were $L \sim 26-42 \mathrm{~nm}$ and $\varepsilon \sim(0.59-3.09) \cdot 10^{-3}$, respectively, and decreased with increasing condensation times. Furthermore, on the basis of calculations of $\varepsilon$ and $L$, the average density of dislocations in the bulk and on the boundaries of CSD, and their total concentration were estimated.

\section{Acknowledgments}

This research was supported by the Ministry of Education and Science of Ukraine (Grant No. 0113U000131 and 0112U000772).

\section{References}

[1] U.Ozgur, Ya. I. Alivov, C. Liu, et al, comprehensive review of $\mathrm{ZnO}$ materials and devices, J. Appl. Phys. 89 (2005) 041301-1-103.

[2] A. Moezzi, A. M. McDonagh, M. B. Cortie, Zinc oxide particles: Synthesis, properties and applications, Chem. Eng. J. 185 - 186 (2012) 1-22.

[3] D. S. Dhawale, C. D. Lokhande, Chemical route to synthesis of mesoporous ZnO thin films and their liquefied petroleum gas sensor performance, J. Alloys Compd. 509 (2011) 10092- 10097.

[4] R. Scheer, H.-W. Schock, Chalcogenide Photovoltaics: Physics, Technologies, and Thin Film Devices, WILEY-VCH Verlag GmbH and Co. KGaA, 2011.

[5] J. Fan, Y. Hao, C. Munuera, M. Garcia-Hernandez, F. Guell, E. M. J. Johansson, G. Boschloo, A. Hagfeldt, A. Cabot, Influence of the Annealing Atmosphere on the Performance of $\mathrm{ZnO}$ Nanowire Dye-Sensitized Solar Cells, J. Phys. Chem. C 117(32) (2013) 16349-16356.

[6] J. Fan, Y. Hao, A. Cabot, E. M. Johansson, G. Boschloo, A. Hagfeldt, Cobalt (II/III) redox electrolyte in $\mathrm{ZnO}$ nanowire-based dye-sensitized solar cells, ACS applied materials \& interfaces 5 (6) (2013) 1902-1906.

[7] J. D. Fan, C. Fabrega, R. Zamani, A. Shavel, F. Guell, A. Carrete, T. Andreu, A. M. Lopez, J. R. Morante, J. Arbiol, A. Cabot, Solution-growth and optoelectronic properties of ZnO:Cl@ZnS coreshell nanowires with tunable shell thickness, J. Alloys Compd. 555 (2013) 213-218.

[8] J. Fan, R. Zamani, C. Fábrega, A. Shavel, C. Flox, M. Ibáñez, T. Andreu, A. M. López, J. Arbiol, J. R. Morante, A. Cabot, Solution-growth and optoelectronic performance of $\mathrm{ZnO}: \mathrm{Cl} / \mathrm{TiO} 2$ and $\mathrm{ZnO}: \mathrm{Cl} / \mathrm{ZnxTiOy} / \mathrm{TiO} 2$ core-shell nanowires with tunable shell thickness, J. Phys. D: Appl. Phys. 45 (2012) 415301.

[9] J. Fan, F. Güell, C. Fábrega, A. Fairbrother, T. Andreu, A. M. López, J. R. Morante, A. Cabot, Visible photoluminescence components of solution-grown $\mathrm{ZnO}$ nanowires: Influence of the surface depletion layer, J. Phys. Chem. C 116 (36) (2012) 19496-19502.

[10] J. Fan, F. Guell, C. Fábrega, A. Shavel, A. Carrete, T. Andreu, J. Ramón Morante, A. Cabot, Enhancement of the photoelectrochemical properties of Cl-doped $\mathrm{ZnO}$ nanowires by tuning their coaxial doping profile, Appl. Phys. Lett. 99 (26) (2011) 262102-1-4.

[11] J. D. Fan, A. Shavel, R. Zamani, C. Fabrega, J. Rousset, S. Haller, F. Guell, A. Carrete, T. Andreu, J. Arbiol, J. R. Morante, A. Cabot, Control of the doping concentration, morphology and optoelectronic properties of vertically aligned chlorine-doped $\mathrm{ZnO}$ nanowires, Acta Mater. 59 (17) (2011) 6790-6800.

[12] C. Amutha, A. Dhanalakshmi, B. Lawrence, K. Kulathuraan, V. Ramadas, B. Natarajan, Influence of Concentration on Structural and Optical Characteristics of Nanocrystalline ZnO Thin Films Synthesized by Sol-Gel Dip Coating Method, Progress in Nanotechnology and Nanomaterials 3(1) (2014) 13-18 
[13] T. Prasada Rao, M. C.Santhosh Kumar, A. Safarulla, V. Ganesan, S. R.Barman, C.Sanjeeviraja, Physical properties of $\mathrm{ZnO}$ thin films deposited at various substrate temperatures using spray pyrolysis, Physica B 405 (2010) 2226-2231.

[14] K.V. Gurav, U.M. Patil, S.M. Pawar, J.H. Kim, C.D. Lokhande, Controlled crystallite orientation in $\mathrm{ZnO}$ nanorods prepared by chemical bath deposition: Effect of $\mathrm{H} 2 \mathrm{O} 2$, J. Alloys Compd. 509 (2011) 7723-7728.

[15] Q. Li, J. Bian, J. Sun, J. Wanga, Y. Luo, K. Sun, D. Yu, Controllable growth of well-aligned $\mathrm{ZnO}$ nanorod arrays by low-temperature wet chemical bath deposition method, Appl. Surf. Sci. 256 (2010) 1698-1702.

[16] Z. Y. Wu, J. H. Cai, G. Ni, ZnO films fabricated by chemical bath deposition from zinc nitrate and ammonium citrate tribasic solution, Thin Solid Films 516 (2008) 7318-7322.

[17] S.B. Jambure, S.J. Patil, A.R. Deshpande, C.D. Lokhande, A comparative study of physicochemical properties of CBD and SILAR grown ZnO thin films, Mater. Res. Bull. 49 (2014) 420425.

[18] A. Sahai, N. Goswami, Structural and vibrational properties of $\mathrm{ZnO}$ nanoparticles synthesized by the chemical precipitation method, Physica E 58 (2014) 130-137.

[19] W.-J. Lee, J.-G. Chang, S.-P. Ju, M.-H. Weng, C.-H. Lee, Structure-dependent mechanical properties of ultrathin zinc oxide nanowires, Nanoscale Research Letters 6 (2011) 352-358.

[20] T. Mahalingam, V. S. John, L. S. Hsu, Microstructural Analysis of Electrodeposited Zinc Oxide Thin Films, J. New Mat. Electrochem. Systems 10 (2007) 9-14.

[21] V.D. Mote, Y. Purushotham, B.N. Dole, williamson-hall analysis in estimation of lattice strain in nanometer-sized zno particles, Journal of Theoretical and Applied Physics 6 (2012) 6-12.

[22] T. O.Berestok, D. I.Kurbatov, N. M. Opanasyuk, A. D. Pogrebnjak, O. P. Manzhos, S. M. Danilchenko, Structural properties of $\mathrm{ZnO}$ thin films obtained by chemical bath deposition technique, J. Nano- Electron. Phys. 5(1) (2013) 01001-01004.

[23] Selected Powder Diffraction Data for Education Straining (Search manual and data cards), Published by the International Centre for diffraction data, 432 (1997). JCPDSN 79-0207.

[24] B.E. Warren, X-ray Diffraction. Dover Books on Physics, New York, 1990.

[25] Ja. S. Umanskij, Ju. A. Skakov, A. N. Ivanov, L. N. Rastorgujev, Crystallogaphy, X-ray graph and electronmicroscopy, Moskow, 1982. (in Russian).

[26] S. Ilican, Y. Caglar, M. Caglar, Preparation and characterization of $\mathrm{ZnO}$ thin films deposited by sol-gel spin coating method, J. Optoelectron. Adv. M. 10(10) (2008) 2578 - 2583.

[27] V.V. Kosyak, D.I. Kurbatov, M.M. Kolesnyk, A.S. Opanasyuk, S.N. Danilchenko, Yu.P. Gnatenko, Structural and electrical properties of $\mathrm{ZnS} / \mathrm{CdTe}$ and $\mathrm{ZnTe} / \mathrm{CdTe}$ heterostructures, Mater. Chemis. Phys. 138 (2013) 731-736.

[28] D. Kurbatov, H. Khlyap, A. Opanasyuk, Substrate-temperature effect on the microstructural and optical properties of $\mathrm{ZnS}$ films obtained by close-spaced vacuum sublimation, Phys. Stat. Sol. A. 206(7) (2009) 1549-1557.

[29] S. Adachi, Handbook on Physical Properties of Semiconductors, Springer, 2004.

[30] L. S. Palatnik, M. Ja. Phuks, V. M. Kosevich, The Mechanism of Formation and Substructure of Condensed Films, Moskow, 1972.(In Russian)

[31] T. Mahalingam, V. S. John, G. Ravi, Microstructural characterization of electrosynthesized ZnTe thin films, Cryst. Res. Technol. 37(4) (2002) 329-339. 
[32] Selected Powder Diffraction Data for Education Straining (Search manual and data cards), Published by the International Centre for diffraction data, 432 (1997). JCPDS 024-1460

[33] A. S. Opanasyuk, T. O. Berestok, P. M. Fochuk, A. E. Bolotnikov, R. B. James, Structural and sub-structural features of chemically deposited Zinc-oxide thin films, Proc. of SPIE 8823 (2013) 88230Q-1-6.

[34] G. Sh. Thool, A. K. Singh, R.S. Singh, A. Gupta, Md. A. B. H. Susan, Facile synthesis of flat crystal ZnO thin films by solution growth method: A micro-structural investigation, Journal of Saudi Chemical Society (2014) http://dx.doi.org/10.1016/j.jscs.2014.02.005.

[35] A. Drici, G. Djeteli, G. Tchangbedji, H. Derouiche, K. Jondo, K. Napo, J. C. Bernède, S. Ouro-Djobo, M. Gbagba, Structured $\mathrm{ZnO}$ thin films grown by chemical bath deposition for photovoltaic applications, Phys. stat. sol. (a) 201(7) (2004) $1528-1536$. 